\title{
Single-cell Hi-C for genome-wide detection of chromatin interactions that occur simultaneously in a single cell
}

\author{
Takashi Nagano ${ }^{1}$, Yaniv Lubling ${ }^{2}$, Eitan Yaffe ${ }^{2}$, Steven W Wingett ${ }^{1}$, Wendy Dean ${ }^{3}$, Amos Tanay ${ }^{2}$ \& Peter Fraser ${ }^{1}$
}

\begin{abstract}
${ }^{1}$ Nuclear Dynamics Programme, The Babraham Institute, Cambridge, UK. ${ }^{2}$ Department of Computer Science and Applied Mathematics and Department of Biological Regulation, Weizmann Institute, Rehovot, Israel. ${ }^{3}$ Epigenetics Programme, The Babraham Institute, Cambridge, UK. Correspondence should be addressed to T.N. (takashi.nagano@babraham.ac.uk) or P.F. (peter.fraser@babraham.ac.uk).
\end{abstract}

Published online 5 November 2015; doi:10.1038/nprot.2015.127

$\mathrm{Hi}-\mathrm{C}$ is a powerful method that provides pairwise information on genomic regions in spatial proximity in the nucleus. Hi- $\mathrm{C}$ requires millions of cells as input and, as genome organization varies from cell to cell, a limitation of Hi-C is that it only provides a population average of genome conformations. We developed single-cell Hi-C to create snapshots of thousands of chromatin interactions that occur simultaneously in a single cell. To adapt $\mathrm{Hi}-\mathrm{C}$ to single-cell analysis, we modified the protocol to include in-nucleus ligation. This enables the isolation of single nuclei carrying Hi-C-ligated DNA into separate tubes, followed by reversal of cross-links, capture of biotinylated ligation junctions on streptavidin-coated magnetic beads and PCR amplification of single-cell Hi-C libraries. The entire laboratory protocol can be carried out in 1 week, and although we have demonstrated its use in mouse $T$ helper ( $\left.T_{H} 1\right)$ cells, it should be applicable to any cell type or species for which standard $\mathrm{Hi}-\mathrm{C}$ has been successful. We also developed an analysis pipeline to filter noise and assess the quality of data sets in a few hours. Although the interactome maps produced by single-cell $\mathrm{Hi}-\mathrm{C}$ are sparse, the data provide useful information to understand cellular variability in nuclear genome organization and chromosome structure. Standard wet and dry laboratory skills in molecular biology and computational analysis are required.

\section{INTRODUCTION}

In the interphase nucleus of higher eukaryotes, the genome is nonrandomly organized within the $3 \mathrm{D}$ space to form long-range and trans-chromosomal interactions. This organization is an emerging area of importance, as the function and activity of loci are strongly correlated with their $3 \mathrm{D}$ conformations ${ }^{1,2}$. To explore such chromosome interactions at a genome-wide level, chromosome conformation capture (3C)-based high-throughput methods, in particular $\mathrm{Hi}-\mathrm{C}$, have been extensively used ${ }^{3-5}$. $\mathrm{Hi}-\mathrm{C}$ measures pairwise contact frequencies between all loci in the genome using populations of millions of cells. These data have led to advances in the understanding of higher-order organization of the genome, such as chromatin loop formation and the discovery of topologically associating domains ${ }^{6-8}$, and they have been used to build 3D models of chromatin ${ }^{3,9,10}$. However, it is important to note that $\mathrm{Hi}-\mathrm{C}$ data represent an ensemble average of millions of cells, and decades of microscopy studies have shown that nuclear organization is not uniform, even among cells of a homogeneous population ${ }^{11}$. Thus, the actual genome organization of an individual cell cannot be determined from ensemble Hi-C.

\section{Development of the protocol}

In conventional $\mathrm{Hi}-\mathrm{C}$, cross-linked chromatin in millions of cells is digested with a restriction enzyme, followed by biotin fill-in labeling of the digested ends. After nuclear lysis and dilution of chromatin complexes, DNA fragments in the same cross-linked complex are ligated and sheared, and ligation junctions are recovered on streptavidin-coated beads before paired-end sequencing ${ }^{12}$. To develop single-cell $\mathrm{Hi}-\mathrm{C}$, we modified the original $\mathrm{Hi}-\mathrm{C}$ protocol $^{12}$ to perform the ligation in the nucleus ${ }^{13}$, allowing us to isolate single cells in which the $\mathrm{Hi}-\mathrm{C}$ procedure was nearly complete. Cells were then transferred to individual tubes for cross-link reversal, DNA fragmentation, capture of ligation junctions and Hi-C library construction (Fig. 1). Despite these technical differences, we confirmed that the single-cell $\mathrm{Hi}-\mathrm{C}$ protocol produces data similar to conventional ensemble $\mathrm{Hi}-\mathrm{C}$ by comparing pooled single-cell Hi-C data from multiple cells ${ }^{13}$. Our more recent analyses, and those of others, suggest that in-nucleus ligation actually improves $\mathrm{Hi}-\mathrm{C}$ results ${ }^{14,15}$.

We also developed computer scripts (scell_hicpipe) to filter spurious read-pairs and assess the quality of single-cell Hi-C data sets; the most recent versions of these scripts and a test data set are available at https://bitbucket.org/tanaylab/schic_pipeline.git. The rationale behind these scripts is described in detail in the supplementary information of Nagano et al. ${ }^{13}$, which can be found here: http://www.nature.com/nature/journal/v502/n7469/extref/ nature12593-s1.pdf.

The scell_hicpipe takes mapped paired-end reads and filters out the read-pairs that are likely to be noise (e.g., read-pairs appearing only once in the sequence output), and it statistically assesses the probability that the data set derives from a single cell. In our recent study ${ }^{13}$, we chose the data sets that satisfy the following three conditions for further in-depth analyses: at least 10,000 unique contacts; the percentage of read-pairs that were sequenced only once (and therefore filtered) was $<30 \%$; and the data set was as expected from a single cell-i.e., the number of autosomal restriction fragment ends (fends) interacting with more than two other distinct fends should be less than the expected number according to a binomial model. Of 74 data sets created in the study, ten satisfied these criteria.

Here we provide a detailed protocol for single-cell $\mathrm{Hi}-\mathrm{C}$ based on our previously published methods ${ }^{13}$. The protocol also describes basic data analysis using the scell_hicpipe scripts via the command line on a Linux operating system.

Applications, advantages and limitations of single-cell Hi-C The interactome obtained with this protocol is not an average among multiple cells but a snapshot from a single cell at the time 


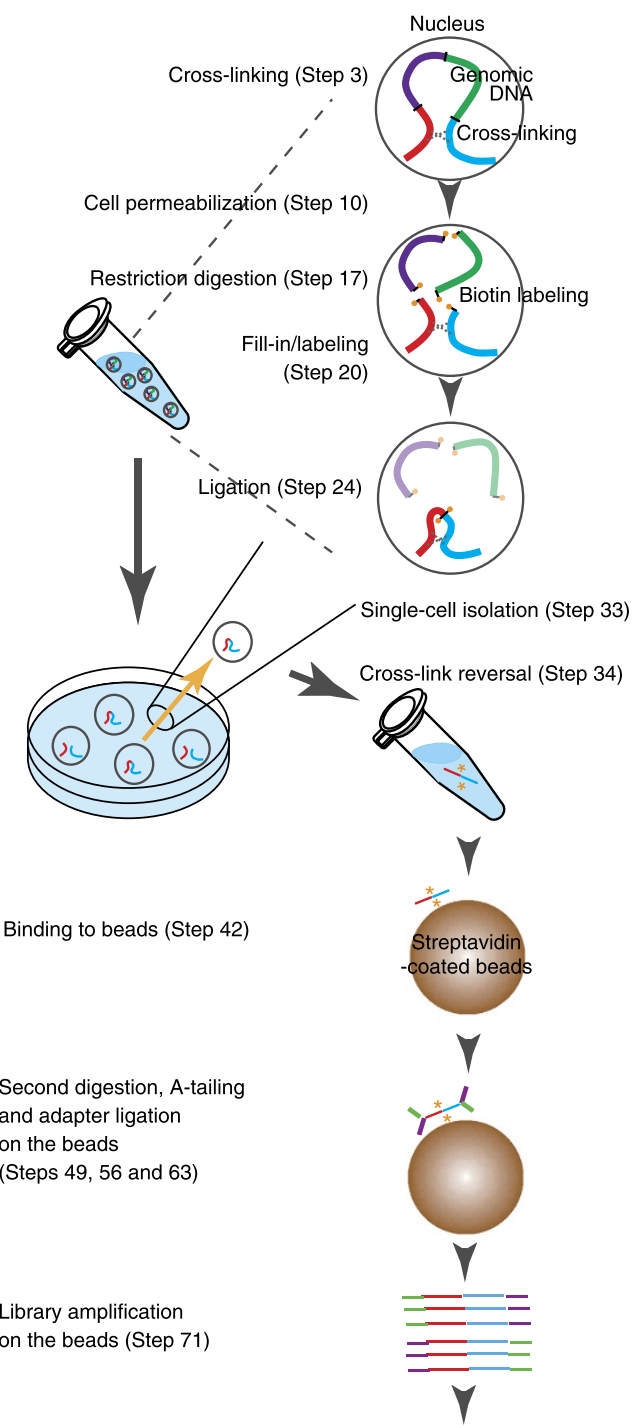

Library purification, size selection, quality control and quantification (Steps 72-80; 81-83; 84 and 85)

Figure 1 | Overview of the single-cell $\mathrm{Hi}-\mathrm{C}$ protocol. Adapted with permission from ref. 13, Nature Publishing Group.

of cell fixation. Therefore, the data provide the opportunity to analyze snapshots of chromosome conformations from individual cells capturing cellular heterogeneity, which may reflect their dynamic behavior. For example, we showed in our singlecell Hi-C study on mouse $\mathrm{T}_{\mathrm{H}} 1$ cells that individual chromosomes maintain topological domain organization at the megabase scale, but that chromosome structures vary from cell to cell at larger scales ${ }^{13}$. An important point to note is that single-cell Hi-C data are sparse, and a potential concern is that the variability in interactome maps derived from individual cells could be because of nonuniform sampling of the interactome from each cell. However, proper statistical analyses can rule out such explanations for the observations.

A distinct advantage of single-cell or single-molecule $\mathrm{Hi}-\mathrm{C}$ data (as in the case of the $\mathrm{X}$ chromosome in male cells) is the ability to apply 3D modeling approaches. For example, the interaction data from the single-copy male $\mathrm{X}$ chromosome was used to derive distance restraints to calculate $3 \mathrm{D}$ models of chromosomes, upon which genomic and epigenomic information can be projected for the study of spatial patterns of such features ${ }^{13}$.

Currently, a major limiting factor for the single-cell Hi-C technique is the sparsity of data or genome coverage. We detected up to $\sim 30,000$ unique interaction pairs per single cell. The theoretical number of distinct mappable interaction pairs in a mouse diploid cell is $\sim 1.2$ million, indicating that the genome coverage from the richest data sets was $\sim 2.5 \%$. Although coverage was low, it was uniform, suggesting that it was unlikely to be due to biased retrieval from the genome. Chromosome structure modeling confirmed this, as combining individual cell data sets led to compact ball-shaped structures with increased violations, rather than a refinement of the models from the initial data sets ${ }^{13}$.

The sparsity of genome coverage leads to concerns over the success rate of the experimental protocol. We showed that the richest data sets-i.e., those with the highest number of restraints (unique read pairs) - generated the most accurate and precise 3D models. In this regard, we chose ten single-cell data sets out of the 74 single cells processed for in-depth statistical analyses, and six of these were used for 3D modeling analyses in our previous study ${ }^{13}$. The low rate of useful libraries is a technical limitation of this protocol. A laboratory automation system to process larger numbers of single cells would obviously increase the number of successful data sets with this protocol. Future work aimed at streamlining or improving the efficiency of individual steps in the single-cell $\mathrm{Hi}-\mathrm{C}$ protocol may also help increase genomic coverage per cell and, in so doing, improve success rates.

However, it is worth noting that despite the technical limitations, there are currently no published alternatives to this single-cell Hi-C protocol.

\section{Experimental design}

Cell type. In general, single-cell $\mathrm{Hi}-\mathrm{C}$ should be possible in any cell preparation in which $3 \mathrm{C}$ or $\mathrm{Hi}-\mathrm{C}$ has been successful. For cells in which $3 \mathrm{C}$ or conventional Hi-C information is not available, it is possible to check the experimental conditions by testing the efficiencies of restriction digestion ${ }^{16}$, biotin labeling and ligation (Box 1) using several million cells.

Cell fixation and permeabilization. In this protocol, cells are fixed in $2 \%$ formaldehyde for $5 \mathrm{~min}$ at room temperature $\left(20-25^{\circ} \mathrm{C}\right)$. However, different conditions (e.g., 1-2\% formaldehyde for $10 \mathrm{~min}$ at room temperature) can also be applied. Generally, stronger fixation conditions (i.e., higher formaldehyde concentration or longer fixation time) may increase the risk of higher background noise in single-cell Hi-C data. For dissociation to single cells and cell permeabilization, additional steps such as trypsin treatment or Dounce homogenizing may be necessary for some cell types ${ }^{17}$.

First restriction enzyme (RE1). The resolution of Hi-C depends on the frequency of restriction enzyme digestion sites in the genome. Therefore, four-cutter enzymes, which have significantly more cut sites in the genome than six-cutter enzymes, have the potential to create higher-resolution interactome maps. The RE1 digestion of the Hi-C protocol is carried out in the presence of detergents, and it is important to note that not every enzyme is suitably active under these conditions. We have used either BglII or DpnII for single-cell Hi-C (BglII in the protocol below), but 


\section{Box 1 | Testing biotin incorporation and Hi-C ligation TIMING 2-3 d}

1. Extract DNA from some of the remaining cells (typically $\sim 5 \times 10^{6}$ ) at Step 27 with DNeasy Blood \& Tissue kit and elute in $100 \mu \mathrm{L}$ of buffer EB (comes with Qiagen's MinElute gel extraction kit).

2. Set up the amplification mixture as tabulated below:

\begin{tabular}{lcc}
\hline Component & Amount per sample $(\boldsymbol{\mu l})$ & Final \\
\hline Eluate from Box 1, step 1 & 1 & \\
PCR buffer, 10× (comes with HotStarTaq enzyme) & 10 & $1 \times$ \\
Water & 85.5 & \\
dNTPs, 10 mM each & 2 & $0.2 \mathrm{mM}$ \\
Amplification primer, $100 \mu \mathrm{M}(\mathrm{F})$ & 0.5 & $0.5 \mu \mathrm{M}$ \\
Amplification primer, $100 \mu \mathrm{M}(\mathrm{R})$ & 0.5 & $0.5 \mu \mathrm{M}$ \\
HotStarTaq DNA polymerase $(5 \mathrm{U} / \mu \mathrm{l})$ & 0.5 & $2.5 \mathrm{U}$ \\
\hline
\end{tabular}

3. Run the amplification reaction in a thermal cycler, using the program below:

\begin{tabular}{lccc}
\hline Cycle number & Anneal & Extend & Denature \\
\hline 1 & & & $95^{\circ} \mathrm{C}, 15$ min \\
$2-39$ & $58{ }^{\circ} \mathrm{C}, 1$ min & $72{ }^{\circ} \mathrm{C}, 1$ min & $94^{\circ} \mathrm{C}, 30 \mathrm{~s}$ \\
40 & $58^{\circ} \mathrm{C}, 2$ min & $72{ }^{\circ} \mathrm{C}, 10$ min & \\
\hline
\end{tabular}

$\triangle$ CRITICAL In this PCR, sets of primers ( $F$ and $R$ above) that are designed to anneal to two neighboring BglII fragments in the same orientation (Fig 4a) are used to detect and amplify Hi-C products (Fig $\mathbf{4 b}$ ).

PAUSE POINT The samples can be kept at $-20^{\circ} \mathrm{C}$ for several days.

4. Purify the PCR products by QIAquick PCR purification kit and elute in $33 \mu \mathrm{l}$ of buffer EB; digest $10 \mu \mathrm{l}$ of the elute with $1 \mu \mathrm{l}$ of either BglII, ClaI or NotI (undigested control) in $15-\mu \mathrm{l}$ scale, and analyze it on an agarose gel (Fig. 4c).

\section{? TROUBLESHOOTING}

Ideally, the DNA should be resistant to BglII digestion (reflecting ligation junctions processed as expected), whereas the ClaI digestion should be near complete, which suggests that BglII digestion and biotin incorporation are efficient. Note that each assessment is only on the specific junction amplified by the primers, and they represent an average efficiency among multiple cells.

other 3C and Hi-C methods have used EcoRI (ref. 18), HindIII (ref. 19), NcoI (ref. 12) and NlaIII (ref. 20). If an enzyme has been used successfully in standard $3 \mathrm{C}$ or $\mathrm{Hi}-\mathrm{C}$ protocols, it is reasonable to assume that the enzyme will work for single-cell $\mathrm{Hi}-\mathrm{C}$. Nevertheless, the efficiency of RE1 digestion should be checked when initiating $\mathrm{Hi}-\mathrm{C}$ studies and in particular when using a restriction enzyme that has not been used for $3 \mathrm{C}$ or $\mathrm{Hi}-\mathrm{C}$ previously. The procedure to check the digestion efficiency has been previously described ${ }^{16}$.

Library barcoding and sequencing. Each single-cell library is barcoded or indexed so that multiple libraries can be mixed in the same sequencing lane and demultiplexed once the sequence data are collected. Because of the greatly reduced complexity of single-cell Hi-C libraries compared with ensemble Hi-C libraries, several single-cell libraries can be multiplexed and still sequenced to reasonable depth. In our recent study ${ }^{13}$ in which RE1 was BglII (approximately one million digestion sites in mouse haploid genome), we loaded up to 12 single-cell $\mathrm{Hi}$-C libraries per lane of an Illumina Genome Analyzer IIx that is capable of 30 million paired-end reads. We found this to be sufficient to determine the quality of single-cell Hi-C libraries, and to achieve near saturation of depth for most libraries ${ }^{13}$. Single-cell libraries of particularly high quality (i.e., sufficient number of fend-pairs, high statistical probability for single-cell sourced data and high percentage of valid read-pair; see ANTICIPATED RESULTS section below) can be resequenced to obtain additional read-pairs, which results in more informative data sets.

\section{MATERIALS}

\section{REAGENTS}

- Fresh single-cell suspension ( $>10^{7}$ cells are preferable to start with) I CAUTION If the cells are directly from animals, approved governmental and institutional regulations for animal work must be adhered to, and experiments should be reported according to the ARRIVE (Animal Research: Reporting in vivo Experiments) guidelines ${ }^{21}$ I CAUTION If you are using cell lines in your research, they should be regularly checked to ensure that they are authentic and are not infected with mycoplasma.

- Full medium appropriate for the cell of choice (we used RPMI 1640 with 5\% (vol/vol) FBS for mouse ex vivo $\mathrm{T}_{\mathrm{H}} 1$ cells for our previous study ${ }^{13}$ )
- Formaldehyde (16\% solution; Agar Scientific, cat. no. R1026)

I CAUTION Follow the appropriate health and safety regulations

to handle formaldehyde solution, as it is toxic.

- PBS, pH 7.4 (10×; Life Technologies, cat. no. 70011-036)

- Water (molecular biology grade; Sigma-Aldrich, cat. no. W4502)

- Glycine (freshly prepared $2 \mathrm{M}$ solution)

- Tris-HCl, pH 8.0 (1 M; Life Technologies, cat. no. 15568-025)

- $\mathrm{NaCl}$ (5 M; Life Technologies, cat. no. 24740-011)

- NP-40 (also known as IGEPAL CA-630; Sigma-Aldrich, cat. no. I8896)

- cOmplete, EDTA-free (Roche Diagnostics, cat. no. 11873580001)

- SDS, 20\% (wt/vol) solution (Bio-Rad Laboratories, cat. no. 161-0418)

- Triton X-100 (20\% (vol/vol); Sigma-Aldrich, cat. no. T8787) 
- BglII (50,000 U/ml; New England Biolabs, cat. no. R0144M); NEBuffer 3 $(10 \times)$ supplied with the enzyme. Alternative enzymes can be used instead, as discussed in Experimental design

- dCTP (10 mM; Life Technologies, cat. no. 18253-013)

- dGTP (10 mM; Life Technologies, cat. no. 18254-011)

- dTTP (10 mM; Life Technologies, cat. no. 18255-018)

- dATP (10 mM; Life Technologies, cat. no. 18252-015)

- Biotin-14-dATP (0.4 mM; Life Technologies, cat. no. 19524-016)

- DNA polymerase I, large (Klenow) fragment (5,000 U/ml; New England Biolabs, cat. no. M0210S)

- NEBuffer 2 (10×; New England Biolabs, cat. no. B7002S)

- T4 DNA ligase reaction buffer (10×; New England Biolabs, cat. no. B0202S)

- BSA (100× (10 mg/ml); New England Biolabs, cat. no. B9001)

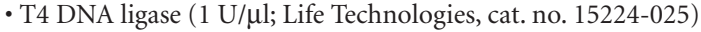

- Agarose, low gelling temperature (Sigma-Aldrich, cat. no. A9414)

- DNeasy blood and tissue kit (Qiagen, cat. no. 69504)

- HotStarTaq DNA polymerase (Qiagen, cat. no. 203203)

- QIAquick PCR purification kit (Qiagen, cat. no. 28104)

- DNA LoBind tube (1.5 ml; Eppendorf, cat. no. 0030 108.051)

- Tris-HCl, pH 7.5 (1 M; Life Technologies, cat. no. 15567-027)

- EDTA, 0.5 M, pH 8.0 (Life Technologies, cat. no. 15575-020)

- Dynabeads M-280 streptavidin (Life Technologies, cat. no. 11205D)

- AluI (10,000 U/ml; New England Biolabs, cat. no. R0137S (comes with NEBuffer $4(10 \times))$ )

- Klenow fragment ( $3^{\prime}-5^{\prime}$ exo-; 5,000 U/ml; New England Biolabs, cat. no. M0212S)

- T4 DNA ligase (2,000,000 U/ml; New England Biolabs, cat. no. M0202M)

- Library amplification primers (for Illumina platform): (F) 5'-AATGATAC GGCGACCACCGAGATCTACACTCTTTCCCTACACGACGCTCTTCCG ATC $^{\star}$ T- $3^{\prime}$; (R) $5^{\prime}$-CAAGCAGAAGACGGCATACGAGATCGGTCTCGGCA TTCCTGCTGAACCGCTCTTCCGATC ${ }^{\star}$ T- $3^{\prime}$; note that the asterisk $\left({ }^{*}\right)$ indicates $5^{\prime}-3^{\prime}$ phosphorothioate linkage) $\Delta$ CRITICAL These oligonucleotides should be 'HPLC-purification grade'.

- Platinum Pfx DNA polymerase (2.5 U/ $\mu$ l; Life Technologies, cat. no. 11708-013 (comes with Pfx amplification buffer (10X) and $50 \mathrm{mM} \mathrm{MgSO}_{4}$ ))

- Agencourt AMPure XP (Beckman Coulter, cat. no. A63881)

$\triangle$ CRITICAL AMPure XP is stored at $4{ }^{\circ} \mathrm{C}$, but make sure that AMPure

$\mathrm{XP}$ added to samples is at room temperature. For convenience, make an aliquot to equilibrate it to room temperature in advance.

- Agarose electrophoresis gel in TBE buffer $(2 \%(\mathrm{wt} / \mathrm{vol}))$

- Glycerol, for molecular biology (Sigma-Aldrich, cat. no. G5516)

- Orange G (Sigma-Aldrich, cat. no. O3756)

- MinElute gel extraction kit (Qiagen, cat. no. 28604)

- Illumina library quantification kit (KAPA Biosystems, cat. no. KK4824)

\section{EQUIPMENT}

- Centrifuge (Heraeus, Megafuge 3.0R)

- Cell strainer ( $40 \mu \mathrm{l}$; Corning, cat. no. 352340)

- Hemocytometer (Weber Scientific)

- Slide glass

- Petri dish

- Pasteur pipettes (Fig. 2a; see Equipment Setup)

- Aspirator tube assemblies for calibrated microcapillary pipettes

(Sigma-Aldrich, cat. no. A5177; Fig. 2b; see Equipment Setup)

- Silicone tubing ( $6.0 \mathrm{~mm}$ bore, 2.0 -mm-thick wall)

- Phase contrast microscope (Nikon TMS)

- Rotating wheel (Stuart SB3)

- Liquid nitrogen in a Dewar flask (Dilvac)

- Benchtop centrifuge (Eppendorf 5417R)

- Thermomixer (Eppendorf, cat. no. EF4283)

- Stereoscopic microscope with more than $60 \times$ magnification (Nikon SMZ800)

Figure 2 | A drawn Pasteur pipette and aspirator tube assembly. Cells are collected by slight suction and capillary action using a mouth-controlled assembly modified to hold a drawn Pasteur pipette. (a) The Pasteur pipette is drawn to a final diameter of $\sim 80 \mu \mathrm{m}$. The final diameter is not crucial, but it greatly aids in the fine control of the cell during collection. The numbers on the ruler shown are in $\mathrm{cm}$. (b) A length of the rubber tubing connecting a red mouth piece and an adapter onto which the Pasteur pipette is fixed through the silicone tubing (see Equipment Setup).
- Hybridization oven (Techne HB-1D)

- Low-retention filter tips (Starlab, cat. nos. S1180-3810, S1180-1810, S1180-8810 and S1182-1830)

- DynaMag-2 magnet (Life Technologies, cat. no. 12321D)

- Thermal cycler (MJ Research PTC-200)

- DynaMag-96 side magnet (Life Technologies, cat. no. 12331D)

- Gel tank (Flowgen Mini Rapide)

- 2100 Bioanalyzer system (Agilent Technologies)

- Real-time PCR system (Bio-Rad CFX96)

- Illumina Genome Analyzer IIx (or HiSeq system; Illumina)

- Perl software package (https://www.perl.org): the scripts used in this protocol have been tested with v5.10.1

- R software package (http://www.r-project.org) with gplots installed: the scripts used in this protocol have been tested with R v3.1.2

- Single-cell Hi-C pipeline (scell_hicpipe; version 1.2); download from https://bitbucket.org/tanaylab/schic_pipeline.git

\section{REAGENT SETUP}

$\Delta$ CRITICAL The volumes given below are to process up to ten million cells and to prepare 12 single-cell Hi-C libraries. These volumes can be scaled up if the number of processed cells is increased, or they can be scaled up or down depending on the number of single-cell samples. However, always prepare extra $(\sim 10 \%)$ to ensure that all samples receive the exact amount indicated in the PROCEDURE.

NP-40, 20\% (vol/vol) To prepare $1 \mathrm{ml}$ of 20\% (vol/vol) NP-40, add $800 \mu \mathrm{l}$ of water to $200 \mu \mathrm{l}$ of NP-40, and mix it well. $\Delta$ CRITICAL Freshly prepare the solution on the day of the cell permeabilization.

Permeabilization buffer Permeabilization buffer is $10 \mathrm{mM}$ Tris- $\mathrm{HCl}, 10 \mathrm{mM}$ $\mathrm{NaCl}$ and $0.2 \%$ (vol/vol) NP-40, cOmplete EDTA-free; to prepare a volume of $50 \mathrm{ml}$, add $500 \mu \mathrm{l}$ of $1 \mathrm{M}$ Tris- $\mathrm{HCl}$ (pH 8.0), $100 \mu \mathrm{l}$ of $5 \mathrm{M} \mathrm{NaCl}$ and $500 \mu \mathrm{l}$ of $20 \%$ ( $\mathrm{vol} / \mathrm{vol}$ ) NP-40 to $48.9 \mathrm{ml}$ of water. Then, add one tablet of cOmplete EDTA-free, mix it well to dissolve the tablet and chill the buffer on ice.

$\triangle$ CRITICAL Freshly prepare the buffer on the day of the cell permeabilization. Triton X-100, 20\% (vol/vol) To prepare $1 \mathrm{ml}$ of $20 \%$ (vol/vol) Triton X-100, add $800 \mu \mathrm{l}$ of water to $200 \mu \mathrm{l}$ of Triton X-100 and mix it well. $\triangle$ CRITICAL Freshly prepare the solution for each restriction digestion. NEBuffer 3, 1.2× To prepare $1.3 \mathrm{ml}$ of $1.2 \times$ NEBuffer 3, add $156 \mu \mathrm{l}$ of NEBuffer $3(10 \times)$ to $1.144 \mathrm{ml}$ of water and mix it well. $\Delta$ CRITICAL Freshly prepare the solution for each restriction digestion.

Binding and washing (BW) buffer, $1 \times$ BW buffer, $1 \times$ is $5 \mathrm{mM}$ Tris- $\mathrm{HCl}$, $0.5 \mathrm{mM}$ EDTA and $1 \mathrm{M} \mathrm{NaCl}$; to prepare a volume of $50 \mathrm{ml}$, add $250 \mu \mathrm{l}$ of $1 \mathrm{M}$ Tris- $\mathrm{HCl}$ (pH 7.5), $50 \mu \mathrm{l}$ of $0.5 \mathrm{M}$ EDTA and $10 \mathrm{ml}$ of $5 \mathrm{M} \mathrm{NaCl}$ to $39.7 \mathrm{ml}$ of water and mix the contents well. We usually freshly prepare the buffer.

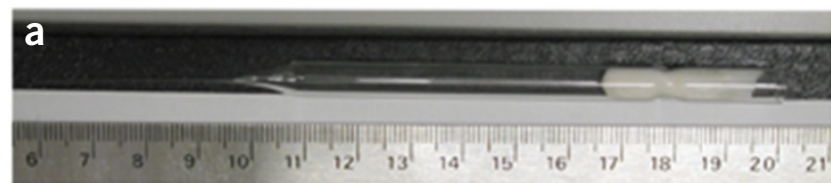

b

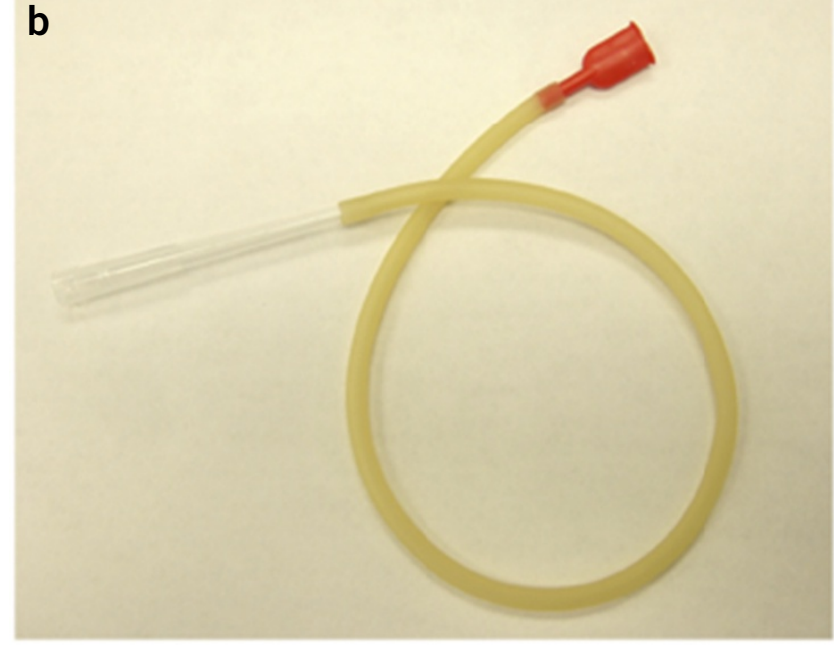


BW buffer, $2 \times$ BW buffer, $2 \times$ is $10 \mathrm{mM}$ Tris- $\mathrm{HCl}, 1 \mathrm{mM}$ EDTA and $2 \mathrm{M}$ $\mathrm{NaCl}$; to prepare a volume of $1 \mathrm{ml}$, add $10 \mu \mathrm{l}$ of $1 \mathrm{M}$ Tris- $\mathrm{HCl}$ (pH 7.5), $2 \mu \mathrm{l}$ of $0.5 \mathrm{M}$ EDTA and $400 \mu \mathrm{l}$ of $5 \mathrm{M} \mathrm{NaCl}$ to $588 \mu \mathrm{l}$ of water and mix it well. We usually freshly prepare the buffer.

EB buffer EB buffer is $10 \mathrm{mM}$ Tris-HCl; to prepare a volume of $15 \mathrm{ml}$, add $150 \mu \mathrm{l}$ of $1 \mathrm{M}$ Tris- $\mathrm{HCl}$ ( $\mathrm{pH} 7.5$ ) to $14.85 \mathrm{ml}$ of water. We usually freshly prepare the buffer.

Oligonucleotides for sequencing adapters (For Illumina sequencing platform) Pairs of two oligonucleotides (forward, F) and (reverse, R) shown in Table 1 should be annealed to prepare the sequencing adapter without the identification tag, or with each corresponding identification tag. p indicates $5^{\prime}$-phosphate modification, and the asterisk $\left(^{*}\right)$ indicates $5^{\prime}-3^{\prime}$ phosphorothioate linkage. Dissolve each adapter to $100 \mu \mathrm{M}$ in water, and make aliquots of $15 \mu \mathrm{l}$. These aliquots can be stored at $-20^{\circ} \mathrm{C}$ for up to 2-3 years. $\triangle$ CRITICAL These oligonucleotides should be 'HPLC-purification grade'.

Annealing of sequencing adapters $(15 \mu \mathrm{M})$ Mix $15 \mu \mathrm{l}$ of $100 \mu \mathrm{M}$ (F) strand with $15 \mu \mathrm{l}$ of $100 \mu \mathrm{M}(\mathrm{R})$ strand of the same tag and add $70 \mu \mathrm{l}$ of water. Transfer the mixture to a $0.2-\mathrm{ml}$ PCR tube and run the following program in a thermal cycler.

\begin{tabular}{ll}
\hline Cycle number & Temperature and duration \\
\hline 1 & $95^{\circ} \mathrm{C}, 5 \mathrm{~min}$ \\
$2-71$ & Decrease by $1^{\circ} \mathrm{C}$ and hold for $1 \mathrm{~min}$ \\
72 & $25^{\circ} \mathrm{C}, 30 \mathrm{~min}$ \\
\hline
\end{tabular}

$\Delta$ CRITICAL Keep it on ice until it is used; however, if it is not used on the same day, make small aliquots $(3-10 \mu \mathrm{l})$ and store them at $-20^{\circ} \mathrm{C}$ for up to 6 months.

Orange G loading dye ( $1 \mathrm{ml})$ Mix $270 \mu \mathrm{l}$ of water, $10 \mu \mathrm{l}$ of $1 \mathrm{M}$ Tris- $\mathrm{HCl}$ ( $\mathrm{pH} 7.5$ ), $120 \mu \mathrm{l}$ of $0.5 \mathrm{M}$ EDTA and $600 \mu \mathrm{l}$ of glycerol; add $1.5 \mathrm{mg}$ of orange $\mathrm{G}$ and mix it well. Store the dye at $-20^{\circ} \mathrm{C}$ for up to 6 months.

EQUIPMENT SETUP

Pasteur pipette with the aspirator tube assembly Draw the Pasteur pipettes by hand in a flame to a diameter of $\sim 80 \mu \mathrm{m}$, and break each one with a diamond pen to create an open end at a right angle to the pipette bore. The tip size and the appearance can be checked under a stereo microscope. Remove the silicone capillary holder (at the left end in Fig. 2b) from the original aspirator tube assembly and, to the adapter, add a $50-\mathrm{mm}$ piece of silicone tubing ( $6.0 \mathrm{~mm}$ bore, 2.0 -mm-thick wall). Insert the Pasteur pipette into the tubing to complete the assembly.
TABLE 1 | Oligonucleotides for sequencing adapters.

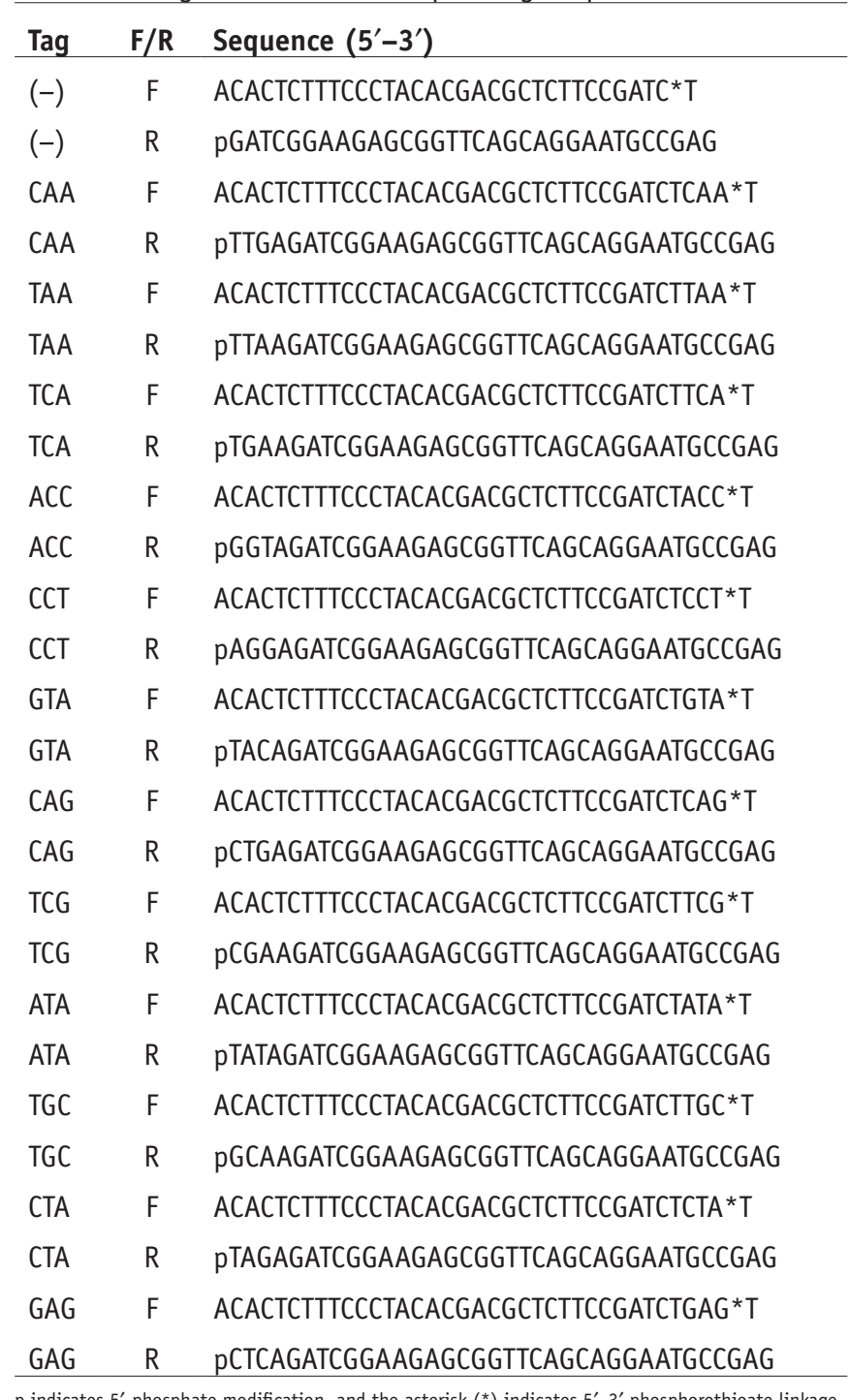

\section{PROCEDURE}

\section{Cell fixation TIMING $30 \mathrm{~min}$ to $1 \mathrm{~h}$}

1) Prepare a fresh single-cell suspension (preferably containing $10^{7}$ cells or more) in $21.875 \mathrm{ml}$ of full medium at room temperature in a $50-\mathrm{ml}$ centrifuge tube.

2| Add $3.125 \mathrm{ml}$ of $16 \%$ formaldehyde, to obtain a final formaldehyde concentration of $2 \%$ in $25 \mathrm{ml}$.

3| Fix for exactly 5 min at room temperature with gentle mixing on a rotating wheel.

I CAUTION As formaldehyde is toxic, it should be handled in a fume hood and discarded according to relevant institutional and local regulations.

4| Quench fixation by adding $1.7 \mathrm{ml}$ of $2 \mathrm{M}$ glycine (final glycine concentration will be $0.127 \mathrm{M}$ ) and mix gently by inverting the tube.

5| Centrifuge the tube at $\sim 300 \mathrm{~g}$ for $8 \min$ at $4^{\circ} \mathrm{C}$. 
6| Remove the supernatant and resuspend the pellet in $50 \mathrm{ml}$ of cold PBS (1x).

$\triangle$ CRITICAL STEP To completely remove the supernatant without disturbing the pellet, do not try to remove all of the supernatant at once. After removing most of the supernatant by pipetting or decanting, with 2-3 ml left, briefly recentrifuge the tube to collect all of the remaining supernatant droplets at the bottom of the tube and carefully remove the remaining supernatant with a $200-$ or $1,000-\mu$ l pipette. This also applies to Step 8 below.

7| Centrifuge the tube at $\sim 300 \mathrm{~g}$ for 8 min at $4^{\circ} \mathrm{C}$.

8| Remove the supernatant as described in Step 6 and proceed to cell permeabilization (Step 9).

PAUSE POINT The cell pellet can be frozen in liquid nitrogen and stored at $-80^{\circ} \mathrm{C}$ for several months.

\section{Cell permeabilization and the first restriction digestion $\bigcirc$ TIMING $3 \mathrm{~h}+$ incubation for $12-16 \mathrm{~h}$}

9| Resuspend the fixed cell pellet from Step 8 in $50 \mathrm{ml}$ of ice-cold permeabilization buffer.

$\triangle$ CRITICAL STEP If it is frozen, the cell pellet should be left on ice until it thaws. Resuspension is most effective by first adding a small volume $(2-3 \mathrm{ml})$ of permeabilization buffer and vigorously tapping the tube, and then adding the remaining buffer.

10| Incubate the tube for 30 min on ice, and mix it by inversion every 5-10 min.

$\Delta$ CRITICAL STEP Mixing is important to ensure high-quality nuclei prep.

11| Centrifuge the tube at $\sim 600 \mathrm{~g}$ for $6 \min$ at $4^{\circ} \mathrm{C}$.

12| Remove most of the supernatant, leaving $\sim 1 \mathrm{ml}$, resuspend the cells with the remaining supernatant, and transfer it to a $1.5-\mathrm{ml}$ tube.

13| Centrifuge the tube at $600 \mathrm{~g}$ for $6 \min$ at $4^{\circ} \mathrm{C}$ in a benchtop centrifuge.

14| Remove the supernatant and wash the pellet twice (once in $800 \mu \mathrm{l}$ and once in $400 \mu \mathrm{l}$ of $1.2 \times$ NEBuffer 3 ).

$\Delta$ CRITICAL STEP Substitute 1.2x NEBuffer 3 buffer with appropriate buffer when you are using a restriction enzyme other than BglII as RE1.

$\Delta$ CRITICAL STEP Resuspending the cell pellet is not necessary at this step. It may even cause cell loss, especially when you are working with a low number of cells.

$\triangle$ CRITICAL STEP Buffer exchange is most efficient by first removing $\sim 90 \%$ of the supernatant; briefly recentrifuge the tube (keeping the same tube orientation so as not to disturb the existing cell pellet) and carefully remove the remaining supernatant with a $20-\mu \mathrm{l}$ pipette. This applies to all subsequent steps involving supernatant removal from 1.5 - $\mathrm{ml}$ tubes after centrifugation.

15 Add $6 \mu \mathrm{l}$ of $20 \%$ SDS (final concentration $0.3 \%$, wt/vol), resuspend the cell pellet and shake at 950 r.p.m. for $1 \mathrm{~h}$ at $37^{\circ} \mathrm{C}$ on a thermomixer.

? TROUBLESHOOTING

16| Add $40 \mu \mathrm{l}$ of $20 \%$ Triton X-100 (final concentration 1.8\%, vol/vol) and shake at 950 r.p.m. for $1 \mathrm{~h}$ at $37{ }^{\circ} \mathrm{C}$ on a thermomixer.

? TROUBLESHOOTING

17| Add 1,500 U of BglII (30 $\mu \mathrm{l}$ of $50 \mathrm{U} / \mu \mathrm{l}$ solution) and shake at 950 r.p.m. at $37{ }^{\circ} \mathrm{C}$ on a thermomixer for $12-16 \mathrm{~h}$. $\Delta$ CRITICAL STEP Replace BglII with the appropriate enzyme when using a restriction enzyme other than BglII as RE1, and adapt the reaction temperature accordingly.

? TROUBLESHOOTING

\section{Biotin labeling and Hi-C ligation TIMING $\sim 90$ min + incubation for $4 \mathrm{~h}$ to overnight}

18| (Optional) If the reaction buffer used for the RE1 digestion is not compatible with Klenow enzyme, a buffer change to NEBuffer 2 will be required. Centrifuge the tube from Step 17 at $600 \mathrm{~g}$ for 6 min at $4{ }^{\circ} \mathrm{C}$, remove the supernatant as described in Step 14 and resuspend the cell pellet in $476 \mu \mathrm{l}$ of NEBuffer $2(1 \times)$. NEBuffers $1-4$ are compatible with Klenow enzyme, but some special buffers such as DpnII buffer (New England Biolabs) are not. 
PROTOCOL

19| Add the following components to the sample and mix them by gentle pipetting:

\begin{tabular}{lcc}
\hline Components & Amount per tube $(\mu \mathrm{l})$ & Final \\
\hline dCTP, $10 \mathrm{mM}$ & 1.5 & $28.4 \mu \mathrm{M}$ \\
dGTP, $10 \mathrm{mM}$ & 1.5 & $28.4 \mu \mathrm{M}$ \\
dTTP, $10 \mathrm{mM}$ & 1.5 & $28.4 \mu \mathrm{M}$ \\
Biotin-14-dATP, 0.4 mM & 37.5 & $28.4 \mu \mathrm{M}$ \\
DNA polymerase I, large (Klenow) fragment & 10 & $50 \mathrm{U}$ \\
\hline
\end{tabular}

20| Incubate the sample at $37^{\circ} \mathrm{C}$ on a thermomixer for $45 \mathrm{~min}$ with intermittent gentle shaking (700 r.p.m. for $10 \mathrm{~s}$ every $30 \mathrm{~s})$.

21| Centrifuge the tube at $600 \mathrm{~g}$ for 6 min at $4^{\circ} \mathrm{C}$.

22| Remove the supernatant, leaving $\sim 50 \mu$ including the pellet.

23| Add the following components to the sample and mix them by gentle pipetting:

\begin{tabular}{lcc}
\hline Components & Amount per tube $(\mu \mathrm{l})$ & Final \\
\hline Water & 830 & \\
T4 ligase buffer, 10x & 100 & $1 \times$ \\
BSA, 100x & 10 & $1 \times$ \\
T4 DNA ligase (Life Technologies; $1 \mathrm{U} / \mu \mathrm{l})$ & 10 & $10 \mathrm{U}$ \\
\hline
\end{tabular}

24 Incubate the sample at $16^{\circ} \mathrm{C}$ for $4 \mathrm{~h}$ or more (overnight is fine). Note that successfully labeled DNA fragment ends (at Step 20) do not reconstitute cleavable BglII restriction sites when ligated during this step.

\section{Single-cell isolation and cross-link reversal $\bigcirc$ TIMING $\sim 1 \mathrm{~h}+$ incubation for 12-16 $\mathrm{h}$}

25| Centrifuge the tube at $600 \mathrm{~g}$ for $6 \mathrm{~min}$ at $4^{\circ} \mathrm{C}$.

26| Remove the supernatant as described in Step 14 and resuspend the pellet with $1 \mathrm{~mL}$ of PBS (1x). Figure 3 shows a typical cell suspension at this stage.

PAUSE POINT The cell suspension can be stored at $4{ }^{\circ} \mathrm{C}$ for several days.

27| Pass the cell suspension through a 40- $\mu \mathrm{m}$ cell strainer and determine the cell density using a hemocytometer. Use an aliquot of 2-5 $\times 10^{6}$ cells to check the efficiency of biotin incorporation and ligation, as described in Box 1 and Figure 4.

$\triangle$ CRITICAL STEP The cell suspension can be stored at $4{ }^{\circ} \mathrm{C}$ for several days. The cell density should be checked before every use. If cell clumps are evident, the suspension should be passed through the cell strainer again and the cell density should be re-assessed.

28| Dilute an aliquot of cells from Step 27 in PBS (1x) to give a suspension of 150 cells/ $\mu$ in $\sim 100 \mu$ l.

29| To a new 1.5-ml tube, add $1 \mathrm{ml}$ of PBS (1x) and $8 \mathrm{mg}$ of low-melting agarose, heat it at $70{ }^{\circ} \mathrm{C}$ in a water bath until the agarose dissolves and then keep the mixture molten at $37^{\circ} \mathrm{C}$.

30| To a new 1.5-ml tube, add $5 \mu$ l of cell suspension from Step 28, $20 \mu$ l of PBS (1x) and $25 \mu$ l of agarose solution from Step 29, and mix well. 


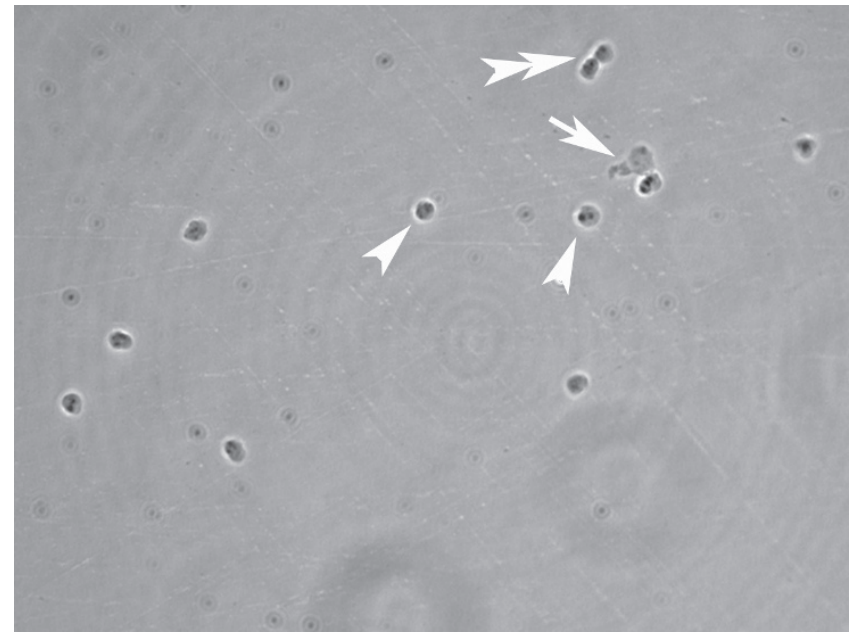

Figure 3 | Example image of the cell suspension after $\mathrm{Hi}-\mathrm{C}$ ligation. Microscopic inspection enables confirmation that cells are singletons and have normal morphology. Arrowheads, single cell; double arrowhead, doublet; arrow, debris.

31| Using a glass Pasteur pipette (preheated to $37^{\circ} \mathrm{C}$ ), take up the cell suspension in agarose and make microdrops (diameter $<0.5 \mathrm{~mm}$; volume $<1 \mu \mathrm{l}$ ) on a new ice-cold glass slide and leave the droplets to solidify. a

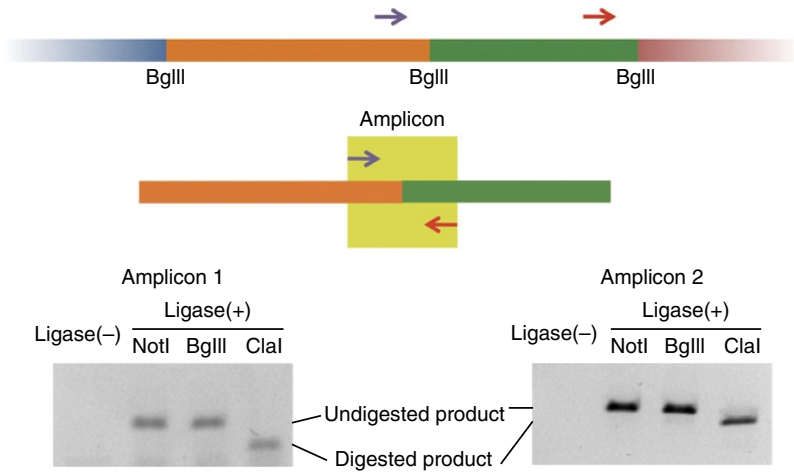

Figure 4 | Analysis of Hi-C ligation junctions. (a) Position of PCR primers (arrows) on genomic DNA BglII fragments. (b) One possible orientation of orange and green fragments after $\mathrm{Hi}-\mathrm{C}$ ligation, in which the two primers designed yield a PCR product. The ligation junction at the middle of the amplicon can be digested with ClaI if biotin labeling is successful. If biotin labeling is unsuccessful, the junction is resistant to ClaI digestion, and it can be digested with BglII. (c) Two examples of gel results showing restriction digestion of $\mathrm{Hi}-\mathrm{C}$ amplicons after high-efficiency biotin labeling (published previously ${ }^{13}$ ). The comparison with ligase minus control (-) confirms that the PCR product is Hi-C ligation-dependent, and near complete digestion with ClaI confirms high efficiency of biotin fill-in. NotI digestion serves as a non-digestion control. Primer sequences for amplicon 1: 5'-CCCTTGTCTTTCCTATGTCTCACCTG-3'; ;'-GATGAGGGCTGAAGGAGAATTAAAG-3'. Primer sequences for amplicon 2: 5'-TGTTGTTCTGTTTCCTCGAAAGAC-3'; $5^{\prime}$-GTGATTTTTACGCCTGGAACGTA-3'. Figure adapted with permission from ref. 13, Nature Publishing Group.

32| Place the slide under PBS (1x) in a Petri dish and, under a stereoscopic microscope, identify droplets that contain only single cells.

\section{? TROUBLESHOOTING}

33| Use a fresh Pasteur pipette connected to a mouthpiece to transfer an isolated single-cell droplet to a new 1.5-mL DNA LoBind tube containing $25 \mu \mathrm{l}$ of PBS (1x).

! CAUTION Mouth pipetting is actively discouraged in many laboratories. A potential alternative is to use a micromanipulator, although this can be cumbersome and time-consuming.

$\Delta$ CRITICAL STEP It is fine to transfer pieces of agarose with a cell. The Pasteur pipette should be changed after handling each cell to avoid contamination.

$34 \mid$ Briefly spin the tube containing the isolated single cell and incubate it at $65^{\circ} \mathrm{C}$ for $12-16 \mathrm{~h}$ to reverse cross-links. In our hands, omission of proteinase $\mathrm{K}$ at this step did not affect results.

$\Delta$ CRITICAL STEP Make sure that the tube lid is tightly closed.

\section{Purification of Hi-C DNA with magnetic beads $\bigcirc$ TIMING $\sim 2 \mathrm{~h}$}

$\triangle$ CRITICAL It is recommended to use low-retention pipette tips for handling beads and single-cell samples after this point. 35| Once cross-link reversal is complete, place the tubes from Step 34 on ice.

36| Mix Dynabeads M-280-streptavidin well to obtain a homogeneous suspension.

37| Transfer $25 \mu \mathrm{l}$ of beads suspension (per single-cell sample) to a fresh $1.5-\mathrm{ml}$ tube.

$\triangle$ CRITICAL STEP For example, take $300 \mu \mathrm{l}$ of bead suspension if you are handling 12 single-cell samples simultaneously.

38| Collect the suspension at the bottom of the tube by gentle and brief centrifugation. Put the tube on a magnetic separation stand for $1 \mathrm{~min}$, and then carefully remove the supernatant. Remove the tube from the magnetic stand, add $1 \times$ BW buffer and gently tap the tube to resuspend the beads.

$\triangle$ CRITICAL STEP The volume of $1 \times$ BW buffer per wash should be equal to or more than the original bead suspension.

39| Repeat Step 38 twice more. 
PROTOCOL

40 Collect the suspension at the bottom of the tube by gentle and brief centrifugation. Put the tube on a magnetic separation stand for $1 \mathrm{~min}$, and then carefully remove the supernatant. Resuspend the beads in $27 \mu \mathrm{l}$ (per single-cell sample) of $2 \times$ BW.

$\triangle$ CRITICAL STEP For example, resuspend the beads with $324 \mu \mathrm{l}$ of $2 \times$ BW buffer if you are handling 12 single-cell samples simultaneously.

41| Transfer $25 \mu \mathrm{l}$ of the bead suspension to each tube containing $25 \mu \mathrm{l}$ of single-cell sample (from Step 35), and gently tap the tube to mix.

$\triangle$ CRITICAL STEP Do not pipette the mixture up and down at this point because DNA is very dilute, and it is prone to loss because of sticking to the pipette tip.

42 Incubate the tube at room temperature for $1 \mathrm{~h}$ on a rotating wheel at 2-5 r.p.m.

43 Collect the suspension at the bottom of the tube by gentle and brief centrifugation. Put the tube on a magnetic separation stand for $1 \mathrm{~min}$, and then carefully remove the supernatant.

44| Remove the tube from the magnetic stand, add $200 \mu \mathrm{L}$ of $1 \times$ BW buffer to each tube and gently tap the tube to resuspend the beads. Collect the suspension at the bottom of the tube by gentle and brief centrifugation. Put the tube on a magnetic separation stand for $1 \mathrm{~min}$, and then carefully remove the supernatant.

45| Repeat Step 44 twice more.

46 Remove the tube from the magnetic stand, add $200 \mu \mathrm{L}$ of EB buffer to each tube and gently tap the tube to resuspend the beads.

Second restriction enzyme (AluI) digestion $\bigcirc$ TIMING $\sim 1.5 \mathrm{~h}$

47| In a new tube, set up AluI reaction mixture as tabulated below:

\begin{tabular}{lcc}
\hline Component & Amount per sample $(\mu \mathrm{l})$ & Final \\
\hline Water & 44 & \\
NEBuffer $4,10 \times$ & 5 & $1 \times$ \\
AluI $(10 \mathrm{U} / \mu \mathrm{l})$ & 1 & $10 \mathrm{U}$ \\
\hline
\end{tabular}

$\Delta$ CRITICAL STEP For multiple samples, always prepare an excess $(\sim 10 \%)$ to ensure that all samples have the exact amount of mixture indicated in the protocol.

48 Collect the suspension from Step 46 at the bottom of the tube by gentle and brief centrifugation. Put the tube on a magnetic separation stand for $1 \mathrm{~min}$, and then carefully remove the supernatant.

49| Remove the tube from the magnet, resuspend the beads with $50 \mu \mathrm{l}$ of AluI reaction mixture (from Step 47) by pipetting gently and incubate the mixture at $37^{\circ} \mathrm{C}$ for $1 \mathrm{~h}$ on a rotating wheel at 2-5 r.p.m.

$\Delta$ CRITICAL STEP The reaction can take place on a small rotating wheel in a hybridization oven.

50| Collect the suspension at the bottom of the tube by gentle and brief centrifugation. Put the tube on a magnetic separation stand for $1 \mathrm{~min}$, and then carefully remove the supernatant.

51 Remove the tube from magnetic stand, add $200 \mu \mathrm{l}$ of $1 \times$ BW buffer to each tube and gently tap the tube to resuspend the beads. Collect the suspension at the bottom of the tube by gentle and brief centrifugation. Put the tube on a magnetic separation stand for $1 \mathrm{~min}$, and then carefully remove the supernatant.

52| Repeat Step 51 twice more.

53| Remove the tube from the magnetic stand, add $200 \mu \mathrm{l}$ of EB buffer to each tube and gently tap the tube to resuspend the beads. 
A-tailing $\bigcirc$ TIMING $\sim 1 \mathrm{~h}$

54| In a new tube, set up the A-tailing reaction mixture as tabulated below:

\begin{tabular}{lcc}
\hline Component & Amount per sample $(\mu \mathrm{l})$ & Final \\
\hline Water & 43 & \\
NEBuffer 2, 10x & 5 & $1 \times$ \\
dATP, $10 \mathrm{mM}$ & 1 & $0.2 \mathrm{mM}$ \\
Klenow $\left(3^{\prime} \rightarrow 5^{\prime}\right.$ exo- $)$ & 1 & $5 \mathrm{U}$ \\
\hline
\end{tabular}

$\triangle$ CRITICAL STEP For multiple samples, always prepare an excess $(\sim 10 \%)$ to ensure that all samples receive the exact amount of mixture indicated in the protocol.

55| Collect the suspension from Step 53 at the bottom of the tube by gentle and brief centrifugation. Put the tube on a magnetic separation stand for $1 \mathrm{~min}$, and then carefully remove the supernatant.

56| Remove the tube from the magnet, resuspend the beads with $50 \mu \mathrm{l}$ of A-tailing reaction mixture (from Step 54) by pipetting gently, and incubate the tube at $37^{\circ} \mathrm{C}$ for 30 min on a rotating wheel at 2-5 r.p.m.

$\triangle$ CRITICAL STEP The reaction can take place on a small rotating wheel in a hybridization oven.

57| Collect the suspension at the bottom of the tube by gentle and brief centrifugation. Put the tube on a magnetic separation stand for $1 \mathrm{~min}$, and then carefully remove the supernatant.

58| Remove the tube from the magnetic stand, add $200 \mu \mathrm{l}$ of $1 \times$ BW buffer to each tube and gently tap the tube to resuspend the beads. Collect the suspension at the bottom of the tube by gentle and brief centrifugation. Put the tube on a magnetic separation stand for $1 \mathrm{~min}$, and then carefully remove the supernatant.

59| Repeat Step 58 twice more.

60| Remove the tube from the magnetic stand, add $200 \mu \mathrm{l}$ of EB buffer to the tube, and gently tap the tube to resuspend the beads.

Adapter ligation $\bigcirc$ TIMING $\sim 1 \mathrm{~h}$

61 In a new tube, set up the adapter ligation mixture as tabulated below and prepare sequencing adapters on ice:

\begin{tabular}{lcc}
\hline Component & Amount per sample $(\mu \mathrm{l})$ & Final \\
\hline Water & 41 & \\
T4 ligase buffer, 10x & 5 & $1 \times$ \\
T4 DNA ligase (New England Biolabs) & 2 & \\
\hline
\end{tabular}

$\Delta$ CRITICAL STEP For multiple samples, always prepare an excess $(\sim 10 \%)$ to ensure that all samples receive the exact amount of mixture, as indicated in the protocol.

$\triangle$ CRITICAL STEP When the adapter without the identification tag is used, all reads theoretically start with TCT, because both ends of the library inserts are created by AluI digestion followed by A-tailing. The identification tags shown in the MATERIALS section appear as the first three bases of the read, followed by TCT, in the sequencing results. This means that the sequencing signals may be less variable when sequencing the first 3-6 bases, depending on the choice of identification tags, which affects cluster recognition by HiSeq sequencer (when using a Genome Analyzer IIx, one can avoid this problem by a specific technique ${ }^{22}$ ). When using HiSeq, make sure that each digit of the tag has substantial variation among the libraries to be loaded in the same lane. The adapters with identification tags should only be used when multiple libraries are to be mixed and sequenced in the same lane.

62 Collect the suspension from Step 60 at the bottom of the tube by gentle and brief centrifugation. Put the tube on a magnetic separation stand for $1 \mathrm{~min}$, and then carefully remove the supernatant. 
63| Remove the tube from the magnet, add $48 \mu \mathrm{l}$ of ligation mixture and $2 \mu \mathrm{l}$ of sequencing adapter (with an identification tag of choice), resuspend the beads by pipetting gently and incubate them at room temperature for 30 min on a rotating wheel at 2-5 r.p.m.

PAUSE POINT The reaction can be extended overnight if necessary.

64| Collect the suspension at the bottom of the tube by gentle and brief centrifugation. Put the tube on a magnetic separation stand for $1 \mathrm{~min}$, and then carefully remove the supernatant.

65 Remove the tube from the magnetic stand, add $200 \mu \mathrm{l}$ of $1 \times$ BW buffer to each tube and gently tap the tube to resuspend the beads. Collect the suspension at the bottom of the tube by gentle and brief centrifugation. Put the tube on a magnetic separation stand for $1 \mathrm{~min}$, and then carefully remove the supernatant.

66| Repeat Step 65 twice more.

67| Remove the tube from the magnetic stand, add $200 \mu \mathrm{l}$ of EB buffer to each tube and gently tap the tube to resuspend the beads.

\section{Library amplification $\bigcirc$ TIMING $\sim 1.5 \mathrm{~h}$}

68| In a new tube, set up the amplification mixture as tabulated below:

\begin{tabular}{lcc}
\hline Component & Amount per sample $(\mu \mathrm{l})$ & Final \\
\hline Water & 36.2 & \\
Pfx amplification buffer, 10x & 5 & $1 \times$ \\
MgSO $_{4}, 50 \mathrm{mM}$ & 2 & $2 \mathrm{mM}$ \\
$\mathrm{dNTPs}_{1} 10 \mathrm{mM}$ & 2 & $0.4 \mathrm{mM}$ \\
Amplification primer, $25 \mu \mathrm{M}(\mathrm{F})$ & 2 & $1 \mu \mathrm{M}$ \\
Amplification primer, $25 \mu \mathrm{M}(\mathrm{R})$ & 2 & $1 \mu \mathrm{M}$ \\
Platinum Pfx DNA polymerase & 0.8 & $2 \mathrm{U}$ \\
\hline
\end{tabular}

CRITICAL STEP For multiple samples, always prepare the mixture in excess $(\sim 10 \%)$ to ensure that all samples receive the exact amount of mixture, as indicated in the protocol.

69| Collect the suspension from Step 67 at the bottom of the tube by gentle and brief centrifugation. Put the tube on a magnetic separation stand for $1 \mathrm{~min}$, and then carefully remove the supernatant.

70| Remove the tube from the magnet, add $50 \mu$ of amplification mixture (from Step 68), resuspend the beads by pipetting gently and transfer them to a new 0.2-ml PCR tube.

71| Run the amplification reaction in a thermal cycler, using the program below:

\begin{tabular}{lccc}
\hline Cycle number & Denature & Anneal & Extend \\
\hline 1 & $94^{\circ} \mathrm{C}, 2$ min & & \\
$2-26$ & $94^{\circ} \mathrm{C}, 15 \mathrm{~s}$ & $62{ }^{\circ} \mathrm{C}, 30 \mathrm{~s}$ & $72^{\circ} \mathrm{C}, 1$ min \\
27 & & & $72^{\circ} \mathrm{C}, 10$ min \\
\hline
\end{tabular}

PAUSE POINT The samples can be kept at $-20^{\circ} \mathrm{C}$ for several days.

\section{Library purification $\bigcirc$ TIMING $\sim 1 \mathrm{~h}$}

72| Briefly centrifuge the amplified library (from Step 71) in a 0.2-mL PCR tube, put on the magnet for 96-well plates for 1-2 min and then carefully transfer $45 \mu \mathrm{l}$ of the supernatant to a new 1.5-ml tube.

$\triangle$ CRITICAL STEP To avoid contamination of the supernatant with beads, take care not to disturb or touch the bead pellet with the pipette tip. 
73 Add $81 \mu$ l of AMPure XP to $45 \mu \mathrm{l}$ of library, mix it well and leave the tube for 5 min at room temperature.

$\triangle$ CRITICAL STEP AMPure XP is stored at $4{ }^{\circ} \mathrm{C}$, but make sure that the AMPure XP added is at room temperature. For convenience, make an aliquot ( $81 \mu \mathrm{l}$ per sample) to equilibrate to room temperature in advance.

74| Collect the suspension at the bottom of the tube by gentle and brief centrifugation. Put the tube on a magnetic separation stand for 2-3 min, and then carefully remove the supernatant.

75| While keeping the tube on the magnet, add $200 \mu \mathrm{l}$ of $70 \%$ (vol/vol) ethanol. Leave it for $30 \mathrm{~s}$ and then carefully remove the supernatant.

A CRITICAL STEP The 70\% (vol/vol) ethanol should be prepared fresh, and it should be used at room temperature.

76| Repeat Step 75 twice more.

77| Remove the tube from the magnetic stand and collect the remaining liquid at the bottom of the tube by gentle and brief centrifugation. Put the tube on a magnetic separation stand, and remove the remaining liquid at the bottom, taking care not to disturb or touch the bead pellet.

78| Open the lid of the tube on the magnet and leave it for 5-15 min until the bead pellet dries.

$\triangle$ CRITICAL STEP The tube can be covered with a clean paper towel. A sign of dry pellets is a loss of glossy surface and visible cracks.

79| Once the pellet is dry, immediately add $17 \mu \mathrm{l}$ of $10 \mathrm{mM}$ Tris- $\mathrm{HCl}(\mathrm{pH} 8.5)$ to the pellet, remove the tube from the magnet, resuspend the pellet well by gentle pipetting and leave it for $5 \mathrm{~min}$.

80 Collect the suspension at the bottom of the tube by gentle and brief centrifugation. Put the tube on a magnetic separation stand for 2-3 min, and then carefully transfer $15 \mu \mathrm{l}$ of the supernatant to a new $1.5-\mathrm{ml}$ tube.

$\triangle$ CRITICAL STEP To avoid contamination of the supernatant with beads, take care not to disturb or touch the bead pellet with the pipette tip.

\section{Size selection of the library $\bigcirc$ TIMING $\sim 5 \mathrm{~h}$}

81| Mix the sample from Step 80 with $3 \mu \mathrm{l}$ of orange $\mathrm{G}$ loading dye and run it on a $2 \%$ (wt/vol) agarose gel until the orange $\mathrm{G}$ dye has migrated $\sim 3 \mathrm{~cm}$.

! CAUTION As ethidium bromide is toxic, it should be handled with care and discarded according to relevant institutional and local regulations.

$\Delta$ CRITICAL STEP Include ethidium bromide in the gel and running buffer at a concentration of $0.5 \mu \mathrm{g} / \mathrm{ml}$.

82| Cut out and collect the gel slice corresponding to 300-700 bp.

$\Delta$ CRITICAL STEP The typical result of the run is a fairly faint smear between 300 and 2,000 bp and a dense band near $130 \mathrm{bp}$, but the intensity of the smear varies. An intense smear is not necessarily indicative of a good library. Care should be taken not to collect the band near $130 \mathrm{bp}$, because it corresponds to the primer dimer that outcompetes sequencing of informative molecules in the library. Figure 5 shows an example gel image with smears of various intensities.

83 Retrieve DNA from the gel fragment using the MinElute gel extraction kit according to the manufacturer's recommendations with the following modifications:

\begin{tabular}{lll}
\hline Manufacturer's original instructions & \multicolumn{1}{c}{ Modification } & Reason \\
\hline $\begin{array}{l}\text { Solubilize a gel slice in buffer QG at } 50{ }^{\circ} \mathrm{C} \\
\text { for } 10 \text { min with vortexing every } 2-3 \mathrm{~min}\end{array}$ & $\begin{array}{l}\text { Solubilize a gel slice in buffer QG at room } \\
\text { temperature for } 30 \text { min on a rotating wheel }\end{array}$ & To minimize DNA damage \\
$\begin{array}{l}\text { To bind DNA to MinElute column, apply the } \\
\text { sample and centrifuge only once }\end{array}$ & $\begin{array}{l}\text { To bind DNA to MinElute column, apply the sample } \\
\text { flow-thorough from the first spin once more }\end{array}$ & To maximize DNA recovery \\
Wash MinElute column with buffer PE once & Wash MinElute column with buffer PE three times & To make sample DNA purer \\
$\begin{array}{l}\text { To elute, wait for } 1 \text { min after adding buffer } \\
\text { EB to MinElute column }\end{array}$ & $\begin{array}{l}\text { To elute, wait for } 10 \text { min after adding buffer EB to } \\
\text { MinElute column }\end{array}$ & To maximize DNA recovery \\
Elute DNA from MinElute column once & $\begin{array}{l}\text { Elute DNA from MinElute column twice (10 } \mu \text { each; } \\
\sim 19 \mu \text { in total) }\end{array}$ & To maximize DNA recovery \\
\hline
\end{tabular}




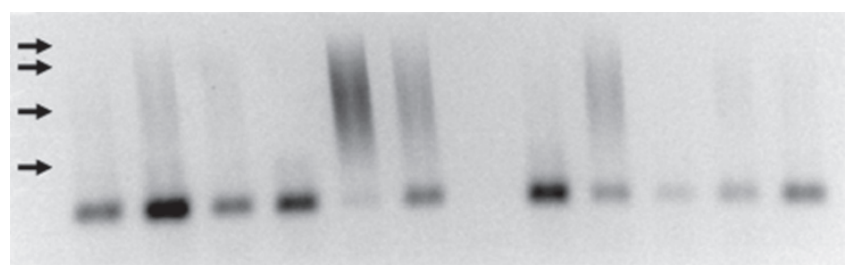

Figure 5 | Example gel image of single-cell Hi-C library smears. Arrows on the left indicate the positions for 2,027, 1,353, 603 and $271 \mathrm{bp}$ from the top, respectively. In our experience, the faint smears like those in the third and eighth lanes from the left are likely to give better results. The bands at the ends of smears are primer dimers, which should be removed as thoroughly as possible at Steps 82 and 83.
Bioanalyzer analysis and quantitative PCR $\bigcirc$ TIMING $\sim 3 \mathrm{~h}$ 84| Assess the quality and size distribution of the library with an Agilent 2100 Bioanalyzer system. As the library was selected for 300-700 bp at Step 82, the size distribution should be close to this size range (Fig. 6).

$\triangle$ CRITICAL STEP If there is another peak $130 \mathrm{bp}$ (Fig. 6a), it means that the library is contaminated with the primer dimer. Even if the primer dimers are minor in the library (e.g., 10\%), they are overrepresented in the sequence results because they are quite efficient in cluster formation. This reduces the sequencing depth of the real library of interest. If the library includes a significant amount of large DNA (e.g., $>1.5 \mathrm{~kb}$ ), they may form large clusters overlapping with neighboring ones in the flowcell. This may make the sequence signals from these clusters of low quality or unreliable. To remove these out-of-range molecules from the library, repeat the size selection (Steps 81-83) once more (Fig. 6b).

\section{? TROUBLESHOOTING}

85 If the size distribution of the library is acceptable for sequencing, quantify the library using KAPA Illumina library quantification kit (which comes with all necessary reagents) and real-time PCR system.

\section{Cluster formation and sequencing $\bigcirc$ TIMING up to 1 week}

86 Sequence the library, 40- to 50-bp paired-end reads, according to the manufacturer's recommendations. This will generate two FASTQ files: one file contains the read 1 sequences and the second file contains the read 2 sequences. $\triangle$ CRITICAL STEP When sequencing with the Genome Analyzer IIx, reasonable sequencing depth is achieved by loading $\sim 12$ single-cell libraries with distinct indexes onto the same lane.

\section{Bioinformatics processing: customizing the single-cell Hi-C pipeline $\bigcirc$ TIMING $2 \mathrm{~d}$}

87| Independently map the two FASTQ files to an appropriate reference genome. In our previous study 13 , we used the Maq aligner program with standard parameters, retaining pairs in which both reads mapped uniquely and with high mapping quality (MapQ $\geq 30)$.

88| Download, set up, test and run scell_hicpipe via the command line on a Linux operating system, as described in Box 2. The description in Box 2 explains how to process a premade test data set to verify that scell_hicpipe runs correctly on your system. However, it is more common that the user will want to process other data sets, which should be done as described in Steps 89-93.

89| Prepare input data file type 1, an ASCII tab-delimited file of mapped single-cell $\mathrm{Hi}-\mathrm{C}$ paired-end reads, with columns ordered as follows: Read1 chromosome name; Read1 co-ordinate; Read1 strand; Read2 chromosome name; Read2 co-ordinate; and Read2 strand.

Copy this file into the 'input' folder.

90| Prepare input file type 2, an ASCII tab-delimited file listing chromosome names and lengths, with columns ordered as follows: Chromosome name; and Chromosome length (in bp).

Copy this file into the 'input' folder. 


\section{Box 2 | Download, set up, test and run the single-cell Hi-C pipeline $\bigcirc$ TIMING $1 \mathrm{~d}$}

The scell_hicpipe scripts and test data set are hosted on the Bitbucket website at the link https://bitbucket.org/tanaylab/schic_pipeline.git. Bitbucket makes use of Git, a distributed version control system, to assist with the collaborative development of software projects. To obtain the pipeline on systems with Git already installed, execute the command git clone https://bitbucket.org/tanaylab/ schic_pipeline.git. Alternatively, navigate to the project download page on Bitbucket using a web browser. The files will be compressed as a zip archive, and they can be extracted in a Unix environment with the following command:

unzip [Zip Archive Filename]

(The pipeline is also available from the Amos Tanay's Group webpages at http://compgenomics.weizmann.ac.il/tanay/?page_id=580.) The pipeline comprises three parts: processing the paired-end reads; producing quality control figures and statistics; and plotting contact maps. To process the reads and perform the quality control, type the following on the command line:

make CFG=input/cell5. cfg

The resulting files will be written to a folder named 'output'. To produce the contact maps, enter on the command line:

plot_cmap CFG=input/cel15.cfg

The figures will be written to the folder output/figures/cmaps/.

91| Prepare an ASCII tab-delimited file of all the fragment ends. Each file should have columns ordered as follows:

Index number (integer value starting and 1 and incrementing by 1); Restriction fragment number; Strand;

Chromosome name; Co-ordinate; Fragment length; and Fend length.

In addition, create a file listing only the predetermined valid fragment ends, which should be in the same format as above. Finally, create a file listing the nonvalid fends, which should simply be a one-column list of the index numbers of those fragments ends not considered valid.

Copy these three files into a folder named 'fends', and copy this folder into the 'input' folder.

\section{Box 3 | Creating a configuration file for each data set $\bigcirc$ TIMING $1 \mathbf{~ h}$}

The makefile is executed to run the pipeline list parameters that may be adjusted by the user. For example, the first parameter in the makefile is as follows:

\# output directory

ODIR?=output

The text after the hash symbol ' $\#$ ' is a comment describing the parameter, which in this case is the directory to which the processed data will be written. The directory name ('outdir') is written after the text '0DIR?='.

The makefile may be edited to specify different running parameters. Alternatively, and more simply, a configuration file may be created to override the parameters specified in the makefile. For example, consider a configuration file containing the following text:

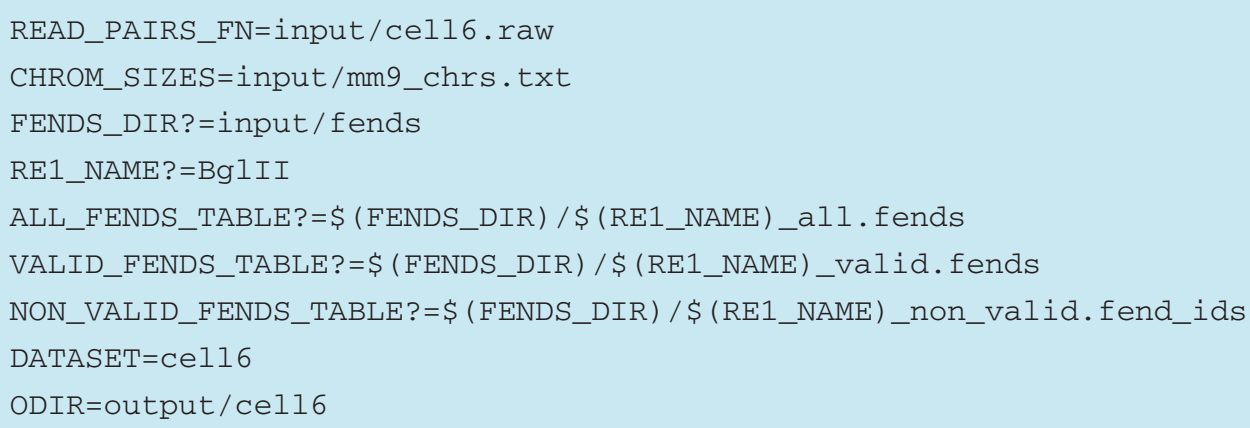

This setup instructs scell_hicpipe that:

(i) The input data set listing the read-pair contacts is named 'cell6.raw', which is found in the 'input' folder.

(ii) The chromosomes list file is named 'mm9_chrs.txt', and it is found in the input folder.

(iii) The fend-files are in a folder named 'fends' in the 'input' folder.

(iv) Name of the restriction enzyme ('BglII') used to create the Hi-C library.

(v) Name and location of the file listing all the fragment ends (input/fends/BglII_all.fends).

(vi) Name and location of the file listing all the valid fragment ends (input/fends/BglII_valid.fends).

(vii) Name and location of the file listing the nonvalid fragment ends (input/fends/BglII_non_valid.fend_ids).

(viii) Output filenames should contain the label 'cell6'.

(ix) Results should be written to the directory 'cell6', in the 'output' folder. 
92| Create a configuration file for each data set, as described in Box 3.

93| To process the reads and to perform the quality control, type the following on the command line:

make CFG=input/[name of configuration file]

The resulting files will be written to a folder named 'output'. To produce the contact maps, enter the following on the command line:

plot_cmap CFG=input/[name of configuration file]

The figures will be written to the folder: output/figures/cmaps/.

\section{? TROUBLESHOOTING}

\section{? TROUBLESHOOTING}

Troubleshooting advice can be found in Table 2.

TABLE 2 | Troubleshooting table.

\begin{tabular}{|c|c|c|c|}
\hline $15-17$ & $\begin{array}{l}\text { Evident cell aggregation } \\
\text { by visual observation in } \\
1.5-\mathrm{ml} \text { tubes }\end{array}$ & $\begin{array}{l}\text { Insufficient resuspension in } \\
\text { the previous } \operatorname{step}(\mathrm{s})\end{array}$ & $\begin{array}{l}\text { Make sure to resuspend the cell pellet well } \\
\text { (but gently to avoid bubbles) at each step. } \\
\text { In general, single cells should be barely } \\
\text { visible in a good single-cell suspension }\end{array}$ \\
\hline Box 1, step 4 & $\begin{array}{l}\text { Inefficient biotin labeling } \\
\text { and } \mathrm{Hi}-\mathrm{C} \text { ligation }\end{array}$ & $\begin{array}{l}\text { Suboptimal conditions for } \\
\text { the enzymes; insufficient cell } \\
\text { permeabilization }\end{array}$ & $\begin{array}{l}\text { Make sure to use fresh permeabilization } \\
\text { buffer. Check the storage conditions of the } \\
\text { enzyme. Make sure to handle DNA polymerase } \\
\text { I, large (Klenow) fragment gently }\end{array}$ \\
\hline 32 & $\begin{array}{l}\text { Agarose drops mostly } \\
\text { contain either two or more } \\
\text { cells, or no cell at all }\end{array}$ & $\begin{array}{l}\text { Inappropriate cell density in } \\
\text { agarose suspension }\end{array}$ & $\begin{array}{l}\text { Reassess the cell density in the original } \\
\text { suspension. Change the cell density in the } \\
\text { agarose suspension at Step } 28\end{array}$ \\
\hline 93 & $\begin{array}{l}\text { Low number of valid read } \\
\text { pairs }\end{array}$ & $\begin{array}{l}\text { Suboptimal conditions } \\
\text { for the first restriction } \\
\text { enzyme; insufficient cell } \\
\text { permeabilization }\end{array}$ & $\begin{array}{l}\text { Make sure to use fresh permeabilization } \\
\text { buffer and Triton X-100 solution. Check } \\
\text { storage conditions of the enzyme. Consider } \\
\text { using an alternative enzyme }\end{array}$ \\
\hline
\end{tabular}

\section{TIMING}

Steps 1-8, cell fixation: 30 min to $1 \mathrm{~h}$

Steps 9-17, cell permeabilization and the first restriction digestion: $3 \mathrm{~h}+$ incubation for $12-16 \mathrm{~h}$

Steps 18-24, biotin labeling and $\mathrm{Hi}-\mathrm{C}$ ligation: $1 \mathrm{~h}$ to $90 \mathrm{~min}+$ incubation for $4 \mathrm{~h}$ to overnight

Steps $25-34$, single-cell isolation and cross-link reversal: $\sim 1 \mathrm{~h}$, depending on the speed of single-cell isolation and the number of single cells to pick up + incubation for 12-16 $\mathrm{h}$

Steps 35-46, sample binding to the magnetic beads: $\sim 2 \mathrm{~h}$, depending on the number of single cells to work on simultaneously Steps 47-53, second restriction enzyme digestion: $\sim 1.5 \mathrm{~h}$, depending on the number of single cells to work on simultaneously Steps 54-60, A-tailing: $\sim 1 \mathrm{~h}$, depending on the number of single cells to work on simultaneously Steps 61-67, adapter ligation: $1 \mathrm{~h}$, depending on the number of single cells to work on simultaneously Steps $68-71$, library amplification: $\sim 1.5 \mathrm{~h}$, depending on the number of single cells to work on simultaneously Steps $72-80$, library purification: $\sim 1 \mathrm{~h}$, depending on the number of single cells to work on simultaneously Steps $81-83$, size selection of the library: $\sim 5 \mathrm{~h}$, depending on the number of single cells to work on simultaneously Step 84, Agilent 2100 Bioanalyzer analysis: $\sim 1 \mathrm{~h}$, depending on the number of single cells to work on simultaneously Step 85 , quantitative PCR of the library: $\sim 2 \mathrm{~h}$, depending on the number of single cells to work on simultaneously Step 86, cluster formation and sequencing: several days up to 1 week Step 87-93, bioinformatics analysis-pre-processing data and using the single-cell $\mathrm{Hi}-\mathrm{C}$ pipeline: $2 \mathrm{~d}$ 
Box 1, testing biotin incorporation and $\mathrm{Hi}-\mathrm{C}$ ligation: 2-3 d

Box 2, download, set up, test and run the single-cell $\mathrm{Hi}-\mathrm{C}$ pipeline: $1 \mathrm{~d}$

Box 3, creating a configuration file for each data set: $1 \mathrm{~h}$

\section{ANTICIPATED RESULTS}

Sequenced single-cell $\mathrm{Hi}-\mathrm{C}$ libraries will need to be demultiplexed. In this protocol, the indices constitute the first four base pairs of the forward read in combination with the first four base pairs of the reverse read. This information is obtained by processing the FASTQ files generated after paired-end sequencing. The barcode sequences should be removed before mapping, as these will most likely not align to the reference genome and their presence would substantially reduce mapping efficiency. The reads are then mapped to the genome to determine the corresponding BglII sites. This enables removal of unmappable reads, noninformative read-pairs (e.g., read-pairs derived from self-ligation of a single BglII fragment and so on) and abnormal read-pairs (e.g., where each read is not at the first AluI site from the corresponding BglII site), to end up with normal ligation read-pairs (see Nagano et al. ${ }^{13}$ for details). The actual read-pair counts and classification for several successful single-cell $\mathrm{Hi}-\mathrm{C}$ libraries are shown in Figure 7.

Because the single-cell library is amplified through $P C R$ before sequencing, a single ligation event between two different BglII sites in the single cell from which

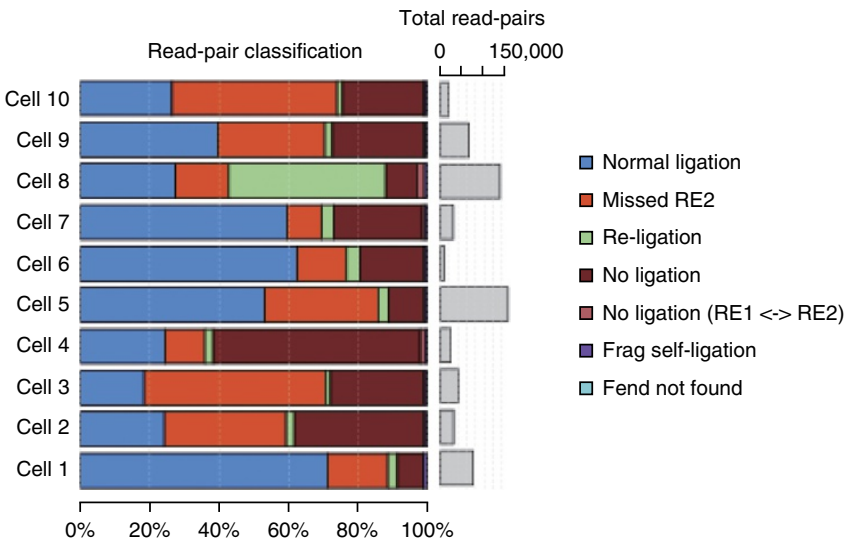

Figure 7 | Classification and total read-pair numbers for ten single-cell data sets. Cells 1, 3, 5, 8 and 9 represent combined data sets formed by adding the original and re-sequencing data of the same libraries. Data sets including re-sequencing data have more read-pair numbers, but they do not necessarily have more unique fend-pairs in Table 3, showing the saturation of sequencing depth. See the original publication ${ }^{13}$ for the definitions of read-pair classifications. Adapted with permission from ref. 13, Nature Publishing Group. the library originates is usually supported by multiple, identical, read-pairs. The processing of read-pairs in a $\mathrm{Hi}-\mathrm{C}$ data set thus comes down to the pairing of two BglII fragment ends (fends), which is denoted as a 'fend-pair'. In theory, a particular BglII fend on an autosome should not be found in more than two different fend-pairs in a single-cell data set from a diploid cell in the $\mathrm{G} 1$ phase of the cell cycle. In male cells, fends from the $X$ chromosome should not be present in more than one fend-pair. The absence of overrepresented fends does not guarantee a single-cell source of the library, and the presence of a small number of over-represented fends does not necessarily mean that the source cell number is greater than one. A data set with a minimal number of over-represented

TABLE 3 | Information on ten single-cell data sets.

\begin{tabular}{|c|c|c|c|c|c|c|c|c|}
\hline \multirow[b]{2}{*}{ Sample } & \multirow[b]{2}{*}{ RE1 } & \multirow{2}{*}{$\begin{array}{l}\text { Unique fend- } \\
\text { pairs }\end{array}$} & \multirow{2}{*}{$\begin{array}{c}\text { Single-read } \\
\text { fend-pairs (\%) }\end{array}$} & \multirow{2}{*}{$\begin{array}{c}\text { Normal } \\
\text { ligation (\%) }\end{array}$} & \multirow{2}{*}{$\begin{array}{c}\text { Cis-trans fold } \\
\text { enrichment }\end{array}$} & \multicolumn{3}{|c|}{ Autosomal fends with $>2$ hits } \\
\hline & & & & & & Observed & Predicted & $P$ value \\
\hline Cell 2 & BglII & 27,382 & 9.6 & 24.1 & 5.68 & 5 & 17.87 & $1.17 \mathrm{E}-03$ \\
\hline Cell 3 & BglII & 24,300 & 7.9 & 18.3 & 5.75 & 7 & 12.57 & $5.80 \mathrm{E}-02$ \\
\hline Cell 5 & BglII & 19,373 & 25.9 & 53.0 & 6.20 & 4 & 6.45 & $1.67 \mathrm{E}-01$ \\
\hline Cell 6 & BglII & 16,958 & 8.5 & 62.3 & 7.23 & 4 & 4.30 & 4.43E-01 \\
\hline Cell 7 & BglII & 13,533 & 12.0 & 59.6 & 6.76 & 0 & 2.21 & $6.86 \mathrm{E}-02$ \\
\hline Cell 10 & BglII & 11,159 & 18.5 & 26.4 & 6.32 & 0 & 1.23 & $1.34 \mathrm{E}-01$ \\
\hline
\end{tabular}

Data published previously ${ }^{13}$. Cis-trans fold enrichment is the fold change of the log enrichment of cis fend-pairs over trans fend-pairs (log(observed_cis/expected_cis)/log(observed_trans/expected_trans); calculated assuming genome-wide uniform distribution of fend-pairs). $P$ value of the number of autosomal fends with more than two covering fend-pairs was calculated from the binomial model (see Nagano et al. $\left.{ }^{13}\right)$. 

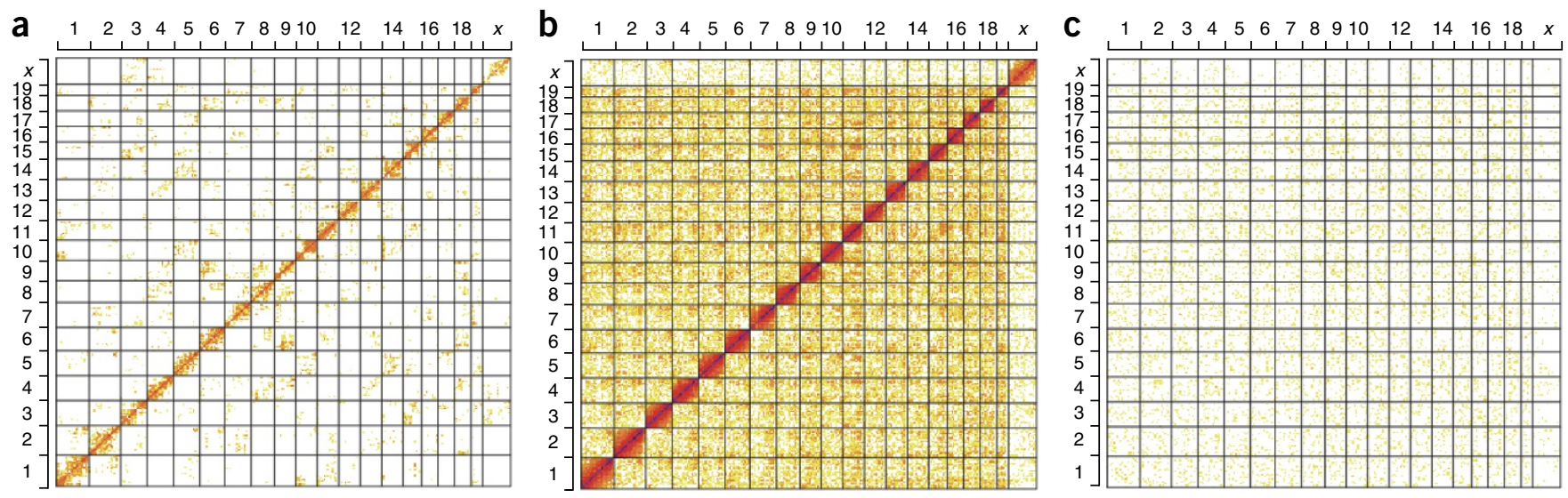

Figure 8 | Genome-wide heatmaps created from $\mathrm{Hi}-\mathrm{C}$ data sets with various quality. Each colored pixel indicates the number of filtered interactions per $10 \times 10 \mathrm{Mb}$ bin, in which yellow means low, orange means low medium, red means high medium and blue means highest density. (a) An example of a high-quality single-cell $\mathrm{Hi}-\mathrm{C}$ data set ${ }^{13}$, in which intense cis-chromosomal interactions and sparse but focal clustering of trans-chromosomal interactions are observed. Reproduced with permission from ref. 13, Nature Publishing Group. (b) Heatmap with suspected multiple cell source, with ubiquitous transchromosomal interactions (as if each chromosome interacts with all other chromosomes) in addition to focal clustering. (c) Example of a poor quality data set, in which enriched cis-chromosomal interactions and focal clustering of trans-chromosomal interactions are not observed.

fends probably derives from a single cell. We found that fend-pairs with only one read are probably noise rather than the results of authentic chromatin proximity in the source cell, and we recommend their removal from the data set. We found that data sets with few single fend-pairs appeared to be of better quality compared with data sets that had many singly occurring fend-pairs. Taking these observations into account, we set three minimum threshold criteria to measure the quality of the single-cell $\mathrm{Hi}-\mathrm{C}$ data set: (A) More than 10,000 fend-pairs; (B) less than $30 \%$ of total read-pairs appear only once in the data set; and $(C)$ the number of autosomal fends that are found in more than two fend-pairs is less than the expected number according to the binomial model.

The scell_hicpipe pipeline gives these data in a summary file found in the 'qc' folder, which in turn is located in the 'output' folder. In the summary file, the column 'Unique amplified fends pairs' lists the number of unique contacts (condition A above). The column 'Perc. of single read fend pairs' reports the percentage of read-pairs that were sequenced only once (condition $B$ above). The results from the binomial test (condition $\mathrm{C}$ above) are written to columns labeled as 'Num 2 chrs fends with 3 obs hits', 'Predicted (binomial) num 2 chrs fends with 3 hits' and 'Pval (binomial) of num 2 chrs fends with 3 hits'.

The actual fend-pair counts and quality control values for several single-cell $\mathrm{Hi}-\mathrm{C}$ libraries published previously ${ }^{13}$ are shown in Table 3.

Another way to gauge the quality of a single-cell $\mathrm{Hi}-\mathrm{C}$ data set is to create a genome-wide heatmap. A heatmap from a successful data set shows (i) an intense accumulation of cis-chromosomal interactions along the diagonal in the map, which decays with distance; and (ii) clear clusters of trans-chromosomal interactions, which indicate contacts between one chromosome and a limited number of other chromosomes. Typical examples of successful and unsuccessful single-cell $\mathrm{Hi}-\mathrm{C}$ heatmaps are shown in Figure 8.

ACKNOWLEDGMENTS The authors thank I. Clay, N. Cope and K. Tabbada for help and support. This work was supported by the Biotechnology and Biological Sciences Research Council, UK.

AUTHOR CONTRIBUTIONS T.N. and P.F. developed and optimized the protocol. Y.L., E.Y. and A.T. contributed to protocol optimization by developing the processing pipeline for single-cell $\mathrm{Hi}-\mathrm{C}$ and analyzing the sequence data. S.W.W. contributed to optimize the pipeline. W.D. contributed the single-cell isolation procedure. T.N., S.W.W. and P.F. wrote the manuscript, with inputs from all other authors.

COMPETING FINANCIAL INTERESTS The authors declare no competing financial interests.

Reprints and permissions information is available online at http://www.nature. com/reprints/index.html.
1. Fraser, P. \& Bickmore, W. Nuclear organization of the genome and the potential for gene regulation. Nature 447, 413-417 (2007).

2. Gibcus, J.H. \& Dekker, J. The hierarchy of the 3D genome. Mol. Cell 49, 773-782 (2013).

3. De Wit, E. \& de Laat, W. A decade of 3 C technologies: insights into nuclear organization. Genes Dev. 26, 11-24 (2012).

4. Ethier, S.D., Miura, H. \& Dostie, J. Discovering genome regulation with 3C and 3C-related technologies. Biochim. Biophys. Acta 1819, 401-410 (2012).

5. Tanay, A. \& Cavalli, G. Chromosomal domains: epigenetic contexts and functional implications of genomic compartmentalization. Curr. Opin. Genet. Dev. 23, 197-203 (2013).

6. Sexton, T. et al. Three-dimensional folding and functional organization principles of the Drosophila genome. Cell 148, 458-472 (2012).

7. Dixon, J.R. et al. Topological domains in mammalian genomes identified by analysis of chromatin interactions. Nature 485, 376-380 (2012). 
8. Nora, E.P. et al. Spatial partitioning of the regulatory landscape of the X-inactivation centre. Nature 485, 381-385 (2012).

9. Dekker, J., Marti-Renom, M.A. \& Mirny, L.A. Exploring the threedimensional organization of genomes: interpreting chromatin interaction data. Nat. Rev. Genet. 14, 390-403 (2013).

10. Furlan-Magaril, M., Várnai, C., Nagano, T. \& Fraser, P. 3D genome architecture from populations to single cells. Curr. Opin. Genet. Dev. 31, 36-41 (2015).

11. Rapkin, L.M., Anchel, D.R.P., Li, R. \& Bazett-Jones, D.P. A view of the chromatin landscape. Micron 43, 150-158 (2012).

12. Lieberman-Aiden, E. et al. Comprehensive mapping of long-range interactions reveals folding principles of the human genome. Science 326, 289-293 (2009).

13. Nagano, T. et al. Single-cell $\mathrm{Hi}-\mathrm{C}$ reveals cell-to-cell variability in chromosome structure. Nature 502, 59-64 (2013).

14. Nagano, T. et al. Comparison of $\mathrm{Hi}-\mathrm{C}$ results using in-solution versus in-nucleus ligation. Genome Biol. 16, 175 (2015).

15. Rao, S.S.P. et al. A 3D map of the human genome at kilobase resolution reveals principles of chromatin looping. Cell 159, 1665-1680 (2014).
16. Sexton, T. et al. Sensitive detection of chromatin coassociations using enhanced chromosome conformation capture on chip. Nat. Protoc. 7, 1335-1350 (2012).

17. Dryden, N.H. et al. Unbiased analysis of potential targets of breast cancer susceptibility loci by capture Hi-C. Genome Res. 24, 1854-1868 (2014).

18. Dekker, J., Rippe, K., Dekker, M. \& Kleckner, N. Capturing chromosome conformation. Science 295, 1306-1311 (2002).

19. Tolhuis, B., Palstra, R.J., Splinter, E., Grosveld, F. \& de Laat, W. Looping and interaction between hypersensitive sites in the active beta-globin locus. Mol. Cell 10, 1453-1465 (2002).

20. Simonis, M., Kooren, J. \& de Laat, W. An evaluation of 3C-based methods to capture DNA interactions. Nat. Methods 4, 895-901 (2007).

21. Kilkenny, C., Browne, W.J., Cuthill, I.C., Emerson, M. \& Altman, D.G. Improving bioscience research reporting: the ARRIVE guidelines for reporting animal research. PLoS Biol. 8, e1000412 (2010).

22. Krueger, F., Andrews, S.R. \& Osborne, C.S. Large scale loss of data in low-diversity illumina sequencing libraries can be recovered by deferred cluster calling. PLOS ONE 6, e16607 (2011). 